\title{
“Orages. Littérature et culture 1760-1830" 18, 2019, dossier Les Révolutions de l'intime, dir. P. KOMPANIETZ et J.-M. ROULIN
}

\section{Paola Perazzolo}

\section{OpenEdition}

\section{Journals}

\section{Édition électronique}

URL : https://journals.openedition.org/studifrancesi/43908

DOI : $10.4000 /$ studifrancesi.43908

ISSN : 2421-5856

\section{Éditeur}

Rosenberg \& Sellier

\section{Édition imprimée}

Date de publication : 1 juin 2021

Pagination : 218-219

ISSN : 0039-2944

\section{Référence électronique}

Paola Perazzolo, «"Orages. Littérature et culture 1760-1830" 18, 2019, dossier Les Révolutions de

l'intime, dir. P. kompanietz et J.-M. Roulin », Studi Francesi [En ligne], 193 (LXV | I) | 2021, mis en ligne le 01 juillet 2021, consulté le 15 octobre 2022. URL : http://journals.openedition.org/studifrancesi/43908 ; DOI : https://doi.org/10.4000/studifrancesi.43908

Ce document a été généré automatiquement le 15 octobre 2022

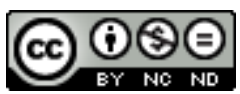

Creative Commons - Attribution - Pas d'Utilisation Commerciale - Pas de Modification 4.0 International - CC BY-NC-ND 4.0

https://creativecommons.org/licenses/by-nc-nd/4.0/ 


\title{
"Orages. Littérature et culture 1760-1830" 18, 2019, dossier Les Révolutions de l'intime, dir. P. KOMPANIETZ et J.-M. ROULIN
}

\author{
Paola Perazzolo
}

\section{RÉFÉRENCE}

“Orages. Littérature et culture 1760-1830" 18, 2019, dossier Les Révolutions de l'intime, dir. P. KOMPANIETZ et J.-M. ROULIN, pp. 11-174.

1 Ainsi que le précise l'Éditorial d'olivier Bara (pp. 7-8), le numéro en question propose, outre les articles composant le «Cahier» - dans les «Varia», Myrtille MÉRICAM-BOURDET, Condorcet et le problème des subsistances sous le ministre Turgot: trois pamphlets pour 1775 (pp. 177-200) et Olivier BARA, Influence des emplois sur la dramaturgie d'Opéra-comique entre Directoire et Empire: d'Elleviou à l'"Elleviou", de Martin au "Martin", enjeux esthétiques et politiques (pp. 201-228), dans la section «Fil Rouge» Jean-Noël PASCAL, De la difficulté d'être un poète personnel: le cas de Louis-Joseph Legay (1759-1823) (pp. 229-242) - un dossier portant sur l'intime comme «construction discursive» (p. 7) pendant les années 1760-1830. Ces années s'avèrent, du point de vue du dossier que nous allons examiner, particulièrement fécondes: la représentation littéraire de l'intime naît en effet avec la Nouvelle Héloïse, évolue de façon inattendue pendant et après la Révolution de 1789 et se structure, au niveau de l'évolution du concept et de ses transpositions littéraires, avant les Odes et Ballades. Dans leur Introduction (pp. 11-32), les co-directeurs Paul Kompanietz et Jean-Marie Roulin expliquent bien que si le terme devient concept autour de 1830, c'est pendant les années mentionnées que l'intime assume des significations inédites. En témoigne une représentation littéraire qui exprime à tel point une «nouvelle manière d'appréhender l'homme et la société, moralement, philosophiquement et 
politiquement» (p. 12) qu'on peut légitimement parler d'une «révolution de l'intime» (p. 13) qui s'accomplit pendant ce «moment 1800» quand l'intime - à ne pas confondre avec le «privé» - se redéfinit en montrant, indépendamment des auteurs et des genres, des traits communs: une approche laïcisée, la conscience de la perte d'unité de l'individu, la valorisation de la faculté de ressentir, la perception d'un lien fort entre individu et dimension sociale et/ou politique.

2 Cette hypothèse de départ, qui sous-tend l'unité chronologique et conceptuelle du dossier, réapparaît comme un fil rouge dans des contributions qui présentent, parmi d'autres mérites, celui d'une originalité d'approche qui induit plusieurs auteurs à se pencher sur des textes traditionnellement peu associés au concept en question. C'est notamment le cas de Stéphanie GENAND (L'intime sadien, pp. 33-44), qui analyse la production d'un écrivain n'ayant jamais dévoilé de détails personnels ni, à plus forte raison, publié d'autobiographie - le «concept s'avère chez lui problématique jusqu'à l'introuvable» (p. 33), avoue l'A. même - mais chez qui l'intime ressort comme une étude de cas permettant de mettre en relation l'individu et la collectivité et de signaler l'exceptionnalité du libertin plus que comme un objet moral à (re)présenter ou un dévoilement de soi. Pour sa part, Cyril FRANCÈs («Nous ne nous gênâmes pas pour retenir nos larmes»: les paradoxes de l'intime chez Casanova, pp. 45-60) souligne la dimension contradictoire d'un intime qui est chez le Vénitien «à la fois emphatiquement exposé et pudiquement contenu, dramatiquement valorisé et subrepticement vidé de sa substance» (p. 59) et où le critique retrouve l'exhibition authentique d'une intimité conçue comme inconnaissable et d'une existence qui n'est jamais véritablement dévoilée tout en étant apparemment détaillée. Les deux contributions suivantes se focalisent sur des textes d'émigrés articulant différemment le rapport entre fiction de l'intime et Histoire pendant la décennie révolutionnaire: Romain ENRIQUEZ (De l'intime à l'inconscient: "Voyage autour de ma chambre" de Xavier de Maistre, pp. 61-74) analyse ce «faux journal intime» (p. 64) qui pervertit les codes du genre et présente un dédoublement du sujet aussi troublant qu'il suscitera plus tard l'intérêt des scientifiques et des psychanalystes tout en faisant l'objet d'une récupération ésotérique, tandis que Paul KOMPANIETZ (L'intime des révolutions dans "L'Émigré" de Sénac de Meilhan, pp. 75-86) retrouve dans le roman du titre la «trace intime» (p. 76) d'une Révolution dont les bouleversements sont tout aussi (ou même plus) perceptibles dans les lettres décrivant l'intime (en révolution) d'émigrés à l'identité incertaine que dans des méditations historiques ou politiques telle la célèbre lettre du président de Longueil.

D'une Révolution à l'autre, en passant par le Tournant des Lumières. Dans La conquête de l'autonomie sentimentale dans les romans de Gacon-Dufour (pp. 87-100), Olivier RITZ met en discussion la doxa critique sur Gacon-Dufour, dont la défense théorique des droits à l'instruction féminine a été qualifiée de «modérée» mais dont l'audace s'expose dans des romans où la possibilité d'un intime féminin «conditionnée par l'instruction [...], par les conditions de vie [...] et par l'état de la société» (p. 99) dessine finalement un «projet politique» (ibidem) visant le bonheur collectif, alors que Jean-Marie Roulin ( $\mathrm{La}$ mort: l'ultime de l'intime (Chateaubriand, Constant, Staël), pp. 101-116) se concentre sur la restitution littéraire de la confrontation à la mort chez les trois écrivains du titre. Dans les lettres et les journaux intimes, leur approche respective de cet événement «capital dans l'écriture intime du moment 1800» (p. 103) relève d'une perspective morale ou philosophique influencée par l'actualité historique et politique récente et catalyse 
d'après des modalités inédites plusieurs débats inhérents à l'intime - la nature de l'existence, la dimension privée du corps, la dimension intime de la veille, du deuil et des dernières volontés du mourant qui retracent tout un monde d'affections.

4 Pour finir, Apolline STRÈQUE (Écrire l'intime en voyage: Stendhal et ses voyages italiens, pp. 117-130) aborde un genre peu canonique par rapport au thème choisi en retraçant la part d'autoanalyse et de mise en scène du moi que le voyage en Italie permet chez Stendhal, dont «l'écriture viatique [...] est contaminée par l'écriture intime» (p. 122) dans sa forme même tout en restant confrontée à (et motivée par) l'Histoire, alors que dans Alchimies de la douleur: George Sand et la littérature intime (pp. 131-148) Brigitte DIAZ prend en considération des écrits personnels et des essais théoriques de Sand. Dans ceux-ci, l'A. participe à la "révolution» de l'intime et de l'intimisme littéraire en concevant la transposition de l'intime (et surtout de la douleur) comme une façon de parler de soi pour soigner les autres et en lui attribuant une valeur éthique dont l'intuition pose «les bases d'une autre conception du moi, qu'elle pense tout entier traversé et constitué par l'altérité» (p. 146) tout en ouvrant la voie à la décennie à venir.

5 Complètent le dossier la publication par Cyril Francès ("Je suis seule et j'aime à l'être»: Lettres de Manon Phlipon (Mme Roland) aux sceurs Cannet, pp. 149-174) de quatre lettres de l'A. du titre traitant des fonctions et des enjeux du texte intime par excellence qu'est le texte épistolaire et un intéressant entretien accordé aux co-directeurs par Michelle Perrot (Toute la littérature dit l'intime, pp. 243-249). Réunissant des contributions qui ont fait l'objet d'un séminaire organisé par le groupe de recherche «moment 1800», ce dossier fort cohérent propose des analyses sur les différentes modalités de transposition littéraire de l'intime originales et convaincantes dans leur démonstration de l'hypothèse de départ d'une «révolution» du concept qui naît avec Rousseau, grandit à l'ombre d'une Révolution qui privilégie officiellement la dimension publique, éclate enfin pendant les années suivantes mais en tout cas bien avant l'époque romantique. 